\title{
Article \\ Characterization of Betulinic Acid-Multiwalled Carbon Nanotubes Modified with Hydrophilic Biopolymer for Improved Biocompatibility on NIH/3T3 Cell Line
}

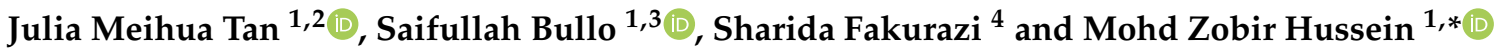 \\ 1 Materials Synthesis and Characterization Laboratory, Institute of Advanced Technology (ITMA), \\ Universiti Putra Malaysia, Serdang 43400, Selangor, Malaysia; juliatan@xmu.edu.my (J.M.T.); \\ saifullah.bullo@bnbwu.edu.pk (S.B.) \\ 2 New Energy Science and Chemical Engineering, Xiamen University Malaysia, Jalan Sunsuria, \\ Bandar Sunsuria, Sepang 43900, Selangor, Malaysia \\ 3 Department of Management Science \& Technology, The Begum Nusrat Bhutto Women University, \\ Sukkur 65170, Sindh, Pakistan \\ 4 Department of Human Anatomy, Faculty of Medicine and Health Sciences, Universiti Putra Malaysia, \\ Serdang 43400, Selangor, Malaysia; sharida@upm.edu.my \\ * Correspondence: mzobir@upm.edu.my
}

\section{check for} updates

Citation: Tan, J.M.; Bullo, S.; Fakurazi, S.; Hussein, M.Z. Characterization of Betulinic Acid-Multiwalled Carbon Nanotubes Modified with Hydrophilic Biopolymer for Improved Biocompatibility on NIH/3T3 Cell Line. Polymers 2021, 13, 1362. https://doi.org/10.3390/polym 13091362

Academic Editor: Dmitri Ossipov

Received: 6 February 2021

Accepted: 26 February 2021

Published: 21 April 2021

Publisher's Note: MDPI stays neutral with regard to jurisdictional claims in published maps and institutional affiliations.

Copyright: (c) 2021 by the authors. Licensee MDPI, Basel, Switzerland. This article is an open access article distributed under the terms and conditions of the Creative Commons Attribution (CC BY) license (https:// creativecommons.org/licenses/by/ $4.0 /)$.

\begin{abstract}
The biocompatibility of carbon nanotubes (CNT) is fairly a challenging task for their applications in nanomedicine. Therefore, the objective of this research was to formulate four types of highly biocompatible betulinic acid-loaded biopolymer nanocomposites, namely chitosan-multiwalled carbon nanotubes (MWBA-CS), polyethylene glycol-multiwalled carbon nanotubes (MWBA-PG), Tween 20-multiwalled carbon nanotubes (MWBA-T2) and Tween 80-multiwalled carbon nanotubes (MWBAT8). The physico-chemical properties of the modified nanocomposites were determined by Fourier transform infrared spectroscopy (FTIR), thermal analysis (TGA) and Raman spectroscopy, while the surface morphology of the resulting nanocomposites was studied using field emission scanning electron microscopy (FESEM). All data revealed that the external surface of MWBA nanocomposites was successfully coated with the respective polymer molecules through hydrophobic and electrostatic interactions with improved thermal profiles. The cell viability assay, which was performed on cultured normal embryonic mouse fibroblast cells, confirmed their excellent biocompatibility in phosphate-buffered saline aqueous media. Overall, our findings herein suggest that the synthesized biopolymer-coated MWBA nanocomposites are promising nanomaterials for drug delivery applications as they enhance the solubility and dispersibility of CNT with significantly reduced cytotoxic effect, especially in normal cells.
\end{abstract}

Keywords: hydrophilic polymer; oxidized nanotubes; cytotoxicity; NIH/3T3 cells; nanomedicine

\section{Introduction}

The concept of nanoscience was first introduced by a Nobel Laureate Caltech physicist, Richard Feynman, in his after-dinner speech entitled "There's plenty of room at the bottom", which was later published in 1960 [1]. In this speech, Feynman addressed the significance of maneuvering materials on a sub-microscopic level as individual atoms could behave differently and that they do not scale down in proportion. Later, this concept was coined as nanotechnology by a Japanese scientist, Norio Taniguchi, in 1974 at an international scientific conference on precision manufacturing technology that described materials with tolerances of a micron or less [2]. The prefix "nanos" is a Greek word meaning dwarf, and one nanometer is a length scale that is equivalent to one billionth of a meter.

Since ancient times, natural products derived from botanical sources have typically been used as traditional remedies to treat sore throats, toothache, colds and influenza due 
to their abundant availability and exceptional chemical and biological features, with macromolecular specificity [3]. Betulinic acid (BA) is a natural phyto-compound mainly isolated from the stem bark of white birch and other tree species widely distributed throughout the tropics. According to research, the pentacyclic triterpene with a lupane structure and its derivative compounds demonstrate potent cytotoxicity for skin cancer cells $[4,5]$ and human immunodeficiency virus [6], while displaying several other pharmacological properties such as anti-bacterial, anti-inflammatory, anti-nociceptive, anti-malarial and anti-helminthic activities [7]. Despite all these advantages, concerns related to issues such as the toxicity of solvent residue, short half-life and low bioavailability due to poor aqueous solubility in the human body present a greater challenge of using BA as a medicine for disease prevention and treatment. To overcome this barrier, the application of nanotechnology in medical therapeutics (this has been termed nanomedicine) can be regarded as a novel and state-of-the-art solution for enhancing the efficacy of a poorly water-soluble drug such as BA, with the utilization of smart nanoscale material (fullerenes, metal particles, carbon nanotubes, organic and inorganic nanoparticles, etc.) acting as the promising drug delivery agent.

Among these nanoscale agents, nanomaterials such as carbon nanotubes (CNT), which possess unique physico-chemical properties, have been extensively researched by scientists in recent years for cancer diagnosis [8], cancer immunotherapy [9], targeted drug delivery [10] and biosensors [11] for their potential applications in nanomedicine. CNT, discovered in 1991 by Japanese scientist lijima [12], are allotropes of carbon made of graphene sheets rolled into nanosized cylindrical tubes with several micrometers in length and nanometer scale in diameter. Based on the number of rolled graphene layers, CNT can be further classified into two main groups: single walled CNT (SWNT) and multiwalled CNT (MWNT). Although these nanomaterials are lightweight, they possess highly conductive electrical and thermal properties while demonstrating ultimate mechanical tensile strength in the range of 100-200 GPa, which is about 100 times stronger than that of steel of the same diameter [13].

In recent years, CNT have been successfully applied as a promising drug delivery vehicle in nanomedicine due to their high specific surface area (internally and externally) and rich electronic polyaromatic structure, which is capable of conjugating with numerous types of therapeutic agents, for example, drugs [10,14], proteins [15], antibodies, [16] genes [17] and vaccines [18] for targeting drug delivery. In addition, oxidized CNT have been reported to display anti-microbial activity against various pathogenic bacteria [19], and they can also be utilized as a potential anti-oxidant in free radical scavenging owing to the presence of carboxylic acid $(-\mathrm{COOH})$ functional groups [20]. One of the most interesting features of these nanomaterials is that they are capable of internalizing into mammalian cells by endocytosis and traveling directly into the cytoplasm and potentially the nucleus [21] for drug delivery, owing to the $\pi-\pi$ stacking and hydrophobic interaction as well as surface electrostatic adsorption. On top of that, they can keep the bioactive drug molecules intact during translocation and cellular penetration without being rapidly metabolized and excreted by the human body [22], and thus further prevent the degradation of the drug. Subsequently, this allows the drug, particularly cytotoxic chemotherapy drugs, to be used at lower dosages and further minimizes the toxic side effects, resulting in greater patient compliance.

With the rapid development of nanomedicine in the 21st century, there have been growing concerns about CNT's possible cytotoxicity that can induce apoptotic cell death and cause mitochondrial impairment through the overproduction of reactive oxygen species [23]. Despite the cellular toxicity, the immunological alterations caused by CNTbased nanomaterials, for example, pulmonary macrophage activation and inflammation induced by the activation of the complement system, can be another potential detrimental concern [24]. The complication of the CNT toxicity issue is contributed by several factors such as shape, length, diameter, purity, surface area and surface functional groups of the nanotubes [25]. When considering their biomedical applications in vitro, the main 
hindrances are their tendency to form agglomerates in the physiological environment resulting from aggregation due to strong van der Waals or electrostatic forces between the nanotubes. This generates an urgent need to adopt alternative methods such as ultrasonication, vigorous agitation, surface chemical treatments, the addition of surfactants or incorporation with water-soluble polymers to improve the overall solubility effect of CNT in aqueous condition.

To address the unmet pharmaceutical needs, we have employed the latter method by using water-soluble polymers (e.g., chitosan and polyethylene glycol) and non-ionic surfactants (e.g., Tween 20 and Tween 80) as the coating agents for our MWNT loaded with BA formulation (herein designated as MWBA). These biopolymers are well known for their intrinsic hydrophilicity, good stability, non-toxicity to the environment and excellent biocompatibility, as well as being commercially inexpensive. They are typically used in numerous biomedical, pharmaceutical and food applications, for example, cartilage tissue engineering [26], wound healing [27], drug delivery [28], food matrix [29] and many more. In addition, the combination of CNT (inorganic component) and biomaterial (organic component) in the administration of cancer immunotherapy may complement each other to promote synergistic effects through enhanced immune reactions of the body to attack the cancer cells [9]. To the best of our knowledge, research related to the biocompatibility of these biopolymers is not sufficiently documented in the literature. Therefore, the biological and safety profiles of these molecules need to be extensively characterized and understood prior to their utilization in the treatment of cancer therapy.

In our previous study, we successfully synthesized an MWBA formulation where it displayed a much more potent anti-cancer activity against the human lung A549 carcinoma cell line and the human liver HepG2 carcinoma cell line than the BA drug alone [30]. However, the cell viability test of the studied material for normal and healthy mouse embryo fibroblast cells showed a much higher toxicity profile at dosages above $50 \mu \mathrm{g} / \mathrm{mL}$. Due to this reason, the primary aim of this work was to assess and compare the cytotoxic effects of the biopolymer-coated MWBA formulations on non-tumor fibroblast cell line $\mathrm{NIH} / 3 \mathrm{~T} 3$ as the preliminary in vitro toxicity screening using MTT ([3-(4,5-dimethylthiazol2-yl)-2,5-diphenyltetrazolium bromide]) colorimetric assay. The nanocomposites were prepared non-covalently through the integration of short, oxidized MWNT loaded with BA into a polymer matrix core shell. The obtained nanocomposites were then subjected to vigorous physico-chemical characterizations and a cell viability biological test.

\section{Materials and Methods}

\subsection{Materials}

Short, oxidized MWNT (MWNT-COOH) produced by chemical vapor deposition was bought from Chengdu Organic Chemicals Co. Ltd. (Chengdu, China) with outside diameter 20-30 nm, length $0.5-2.0 \mu \mathrm{m}$, purity $>95 \mathrm{wt} \%$, $\mathrm{COOH}$ functional content $1-2 \mathrm{wt} \%$ and ash content $<1.5 \mathrm{wt} \%$. Betulinic acid (BA, 90\% purity) with molecular formula $\mathrm{C}_{30} \mathrm{H}_{48} \mathrm{O}_{3}$, Tween 20 (T2), Tween 80 (T8) and partially N-deacetylated chitosan (CS, deacetylation degree $=75-85 \%$, medium molecular weight $=190-310 \mathrm{kDa}$ ) were procured from Sigma Aldrich (Saint Louis, MI, USA). Polyethylene glycol (PG) with an average molecular weight of $300 \mathrm{kDa}$ was obtained from Acros Organics (Geel, Belgium). Methanol and acetic acid (both 99.8\% purity) were sourced from HmbG Chemicals (Hamburg, Germany). All other chemicals and reagents used were of analytical grade.

\subsection{BA Loading onto MWNT-COOH}

The MWBA was prepared following the non-covalent method described previously [30]. BA solution was obtained by dissolving the drug in methanol $(0.125 \mathrm{mg} / \mathrm{mL})$ through stirring and heating to around $37-40{ }^{\circ} \mathrm{C}$ until all BA had fully dissolved. Then, $400 \mathrm{mg}$ of oxidized MWNT was dispersed in BA solution by ultra-sonication treatment for approximately $1 \mathrm{~h}$ to mechanically isolate the bundled nanotubes and enhance their solubility. Subsequently, the suspension was reacted under constant vigorous stirring at room temperature and maintained 
at $\mathrm{pH} 4$ for optimum drug loading. After stirring for $22 \mathrm{~h}$, the mixture was then filtered, centrifuged, washed simultaneously with methanol and deionized water three times and finally dried in an oven at $60{ }^{\circ} \mathrm{C}$ overnight. Later, it was allowed to cool to an ambient temperature to yield MWBA. The sample was homogeneously powdered and kept in an airtight bottle for further use.

\subsection{Surface Coating of Hydrophilic Biopolymer onto MWBA}

Preparation of biocompatible polymeric MWBA nanocomposites was carried out according to the literature with slight modifications [31]. Briefly, $100 \mathrm{mg}$ of synthesized BA-loaded nanotubes were added to $1 \% \mathrm{~T} 2$ dissolved into $100 \mathrm{~mL}$ of deionized water. After that, the mixture was subjected to constant-stirring using a magnetic stirrer at room temperature for $24 \mathrm{~h}$. The black residue was then collected, centrifuged and washed with deionized water three times to remove excessive T2 which was not reacted in the coating process. The resulting product was obtained after drying completely in an oven at $60^{\circ} \mathrm{C}$ overnight. The rest of the biopolymeric MWBA nanocomposites were formulated using a similar method except for $0.5 \%$ CS solution which was prepared by dissolving the CS flakes into $100 \mathrm{~mL}$ of aqueous acetic acid under constant vigorous stirring at room temperature. The samples were denoted as MWBA-T2, MWBA-T8, MWBA-PG and MWBA-CS.

\subsection{UV-vis Spectrophotometry}

The supernatant containing unreacted BA was collected and subjected to spectrophotometric analysis. The determination of BA loading efficiency onto MWNT-COOH was quantified using a Perkin Elmer Lambda 35 UV-vis spectrophotometer (USA). The samples were characterized at a wavelength of $209 \mathrm{~nm}$ (the absorption peak of BA) and the measurement was performed with a quartz cuvette of path length $1 \mathrm{~cm}$. The drug loading efficiency was estimated to be approximately $15 \%$ using the following equation:

Drug loading efficiency $\%=\frac{(\text { Initial amount of BA }- \text { Amount of unreacted BA })}{(\text { Initial amount of BA })} \times 100$

\subsection{Fourier Transform Infrared Spectroscopy}

The chemical structures of MWBA and polymeric MWBA nanocomposites were investigated using a Thermo Nicolet Nexus Smart Orbit FTIR spectrophotometer (USA). The FTIR spectra of the samples were taken in the wavenumber region between 4000 and $400 \mathrm{~cm}^{-1}$ using the $\mathrm{KBr}$ pellet technique except for $\mathrm{T} 2$ and $\mathrm{T} 8$ by a direct deposition technique. To obtain a single spectrum, a total of 32 scans at a resolution of $4 \mathrm{~cm}^{-1}$ were accumulated using a rapid-scan software in OMNIC 8.0. Prior to measurements, all samples were dried in an oven at $60^{\circ} \mathrm{C}$ for $24 \mathrm{~h}$.

\subsection{Thermogravimetric Analysis}

The thermal profiles of the samples were recorded using a TA Q500 thermogravimetric analyzer (USA). The samples were scanned over a temperature range from room temperature to $1000{ }^{\circ} \mathrm{C}$ at a heating rate of $10^{\circ} \mathrm{C} / \mathrm{min}$ under a nitrogen dynamic flow rate of $40 \mathrm{~mL} / \mathrm{min}$. To estimate the $\mathrm{wt} \%$ of the biopolymer coated onto MWBA, thermogravimetric analysis (TGA) was also performed on blank MWNT-COOH coated with the respective hydrophilic biopolymers. A set of four samples designated as MWNT-CS, MWNT-PG, MWNT-T2 and MWNT-T8 were synthesized identically using a similar method as described in Section 2.3 above. The estimated biopolymer content in the samples was found to be around 8.01, 9.13, 18.96 and $59.18 \mathrm{wt} \%$ for MWNT-CS, MWNT-PG, MWNT-T2 and MWNT-T8, respectively, as compared to the blank MWNT-COOH. All samples were dried at $60^{\circ} \mathrm{C}$ for $24 \mathrm{~h}$ to remove the moisture adsorbed on the surface of the samples before carrying out the analysis. 


\subsection{Raman Spectroscopy}

Raman analysis was performed on a WITec confocal Raman microscopy system Alpha 300R (Germany) equipped with a UHTS-300 spectrometer using $532 \mathrm{~nm}$ excitation wavelength. The samples were ultra-sonicated for $10 \mathrm{~min}$ at room temperature and several drops from the suspension were placed on a glass slide prior to the measurements. Raman detailed scans were carried out within the wavenumber range $100-2000 \mathrm{~cm}^{-1}$.

\subsection{Field Emission Scanning Electron Microscopy}

The surface morphology of the samples was observed by the JEOL JSM-7600F and Fei Tecnai G20 field emission scanning electron microscopes operated at an accelerating voltage of 5 and $10 \mathrm{kV}$. The sample was previously dried and ground before being placed in an aluminum sample holder secured on adhesive tape. The sample was then coated with a thin layer of gold using a sputter coater.

\subsection{Determination of Cytotoxicity Properties of Biopolymeric MWBA Nanocomposites}

The in vitro cell viability was conducted on NIH/3T3 cells, a normal and healthy mouse embryonic fibroblast cell line obtained from ATCC using the standard MTT assay. The cells were cultured in a fresh medium containing RPMI supplemented with $10 \%$ fetal bovine serum and $1 \%$ penicillin-streptomycin in a $5 \% \mathrm{CO}_{2}$ atmosphere and $95 \%$ relative humidity at $37^{\circ} \mathrm{C}$ for a period of $24 \mathrm{~h}$. When the confluency of cells reached around $80 \%$, the cell line was then transferred and sub-cultured in a new culture flask for seeding and treatment purposes using $0.25 \%$ trypsin-EDTA solution. Stock solutions containing biopolymeric MWBA nanocomposites were freshly prepared in PBS and diluted serially to obtain a series of concentrations ranging from $1.56 \mu \mathrm{g} / \mathrm{mL}$ to $100 \mu \mathrm{g} / \mathrm{mL}$. The cells cultured without nanocomposites were used as a control group (cells in media only).

For cytotoxicity assay, NIH/3T3 cells were seeded (10,000 cells/well) in a 96-well microplate and maintained for 1 day at $37{ }^{\circ} \mathrm{C}(5 \% \mathrm{CO} 2$ and $95 \%$ air) to allow for cell attachment. The cells were exposed to different concentrations of biopolymeric MWBA nanocomposites for $72 \mathrm{~h}$ and further incubated with MTT solution $(20 \mu \mathrm{L}, 5 \mathrm{mg} / \mathrm{mL}$ in PBS) for another $3 \mathrm{~h}$. Thereafter, excessive MTT reagent was discarded and the purple formazan crystals formed in the assay were solubilized with DMSO $(200 \mu \mathrm{L})$. The absorption was recorded at $570 \mathrm{~nm}$ against $630 \mathrm{~nm}$ as a reference wavelength using an EL 800X microplate reader (Winooski, VT, USA). The following formula was used to determine the absorbance value which is directly proportional to the cell viability. All MTT assays were repeated in triplicate.

$$
\text { Cell Viability } \%=\frac{\left(A_{\text {test }}-A_{\text {blank }}\right)}{\left(A_{\text {control }}-A_{\text {blank }}\right)} \times 100
$$

where $A_{\text {test }}$ is the absorbance of the cells treated with biopolymeric MWBA nanocomposites, $A_{\text {blank }}$ is the absorbance from empty wells and $A_{\text {control }}$ refers to the absorbance of the cells without biopolymeric MWBA nanocomposites.

\subsection{Statistical Analysis}

Each measurement was performed using at least three fresh, independently prepared samples $(n=3)$ and the results were expressed as the mean \pm standard deviation. The data were subjected to one-way analysis of variance (ANOVA) using the SPSS version 25.0 statistical software package (Armonk, NY, USA). Tukey HSD post-hoc test was also applied to determine the significant difference $\left({ }^{*} p<0.05\right)$ between the biopolymeric MWBA nanocomposites using a $95 \%$ confidence interval.

\section{Results and Discussion}

\subsection{FTIR Spectra of MWBA Coated with Biopolymers}

FTIR spectroscopy is a quantitative analytical tool widely used in many research applications as one of the possible ways to elucidate the chemical structure and molecular interaction among the compounds present in a sample [32]. We have reported the FTIR 
spectra of the blank MWNT-COOH and the BA-loaded nanotubes extensively in our previous paper [30]. Hence, in the current study, we focus on the possible interaction between the functional groups of the biopolymers and BA-loaded nanotubes. Figure 1 illustrates the FTIR spectra of the (a) CS, MWBA-CS, PG, MWBA-PG and (b) T2, MWBA-T2, T8 and MWBA-T8. Generally, the characteristic bands that occurred at $2919-2913 \mathrm{~cm}^{-1}$ and $1385-1383 \mathrm{~cm}^{-1}$ (asymmetric and symmetric C-H stretching in methyl and methylene groups) as well as $1632-1630 \mathrm{~cm}^{-1}$ ( $\mathrm{C}=\mathrm{O}$ stretching in carboxylate groups) were attributed to the conjugated BA molecules in all BA-loaded MWNT samples [33].

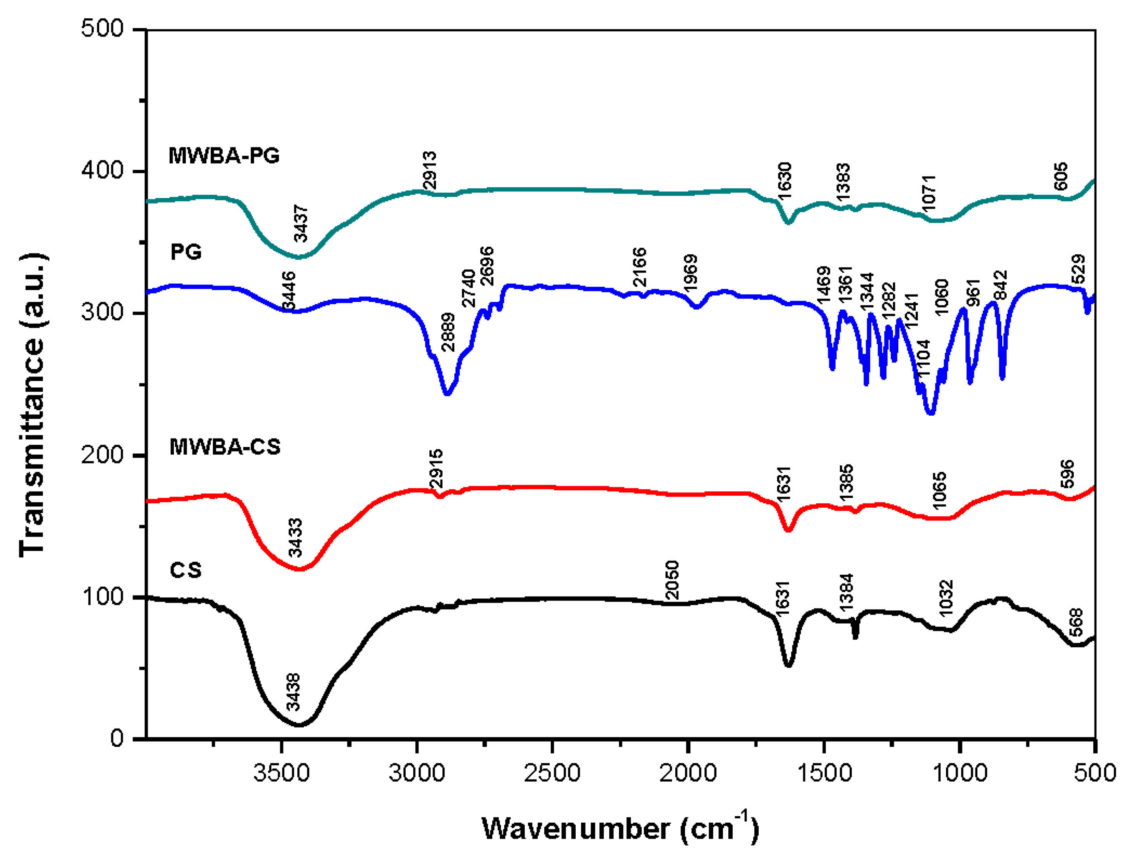

(a)

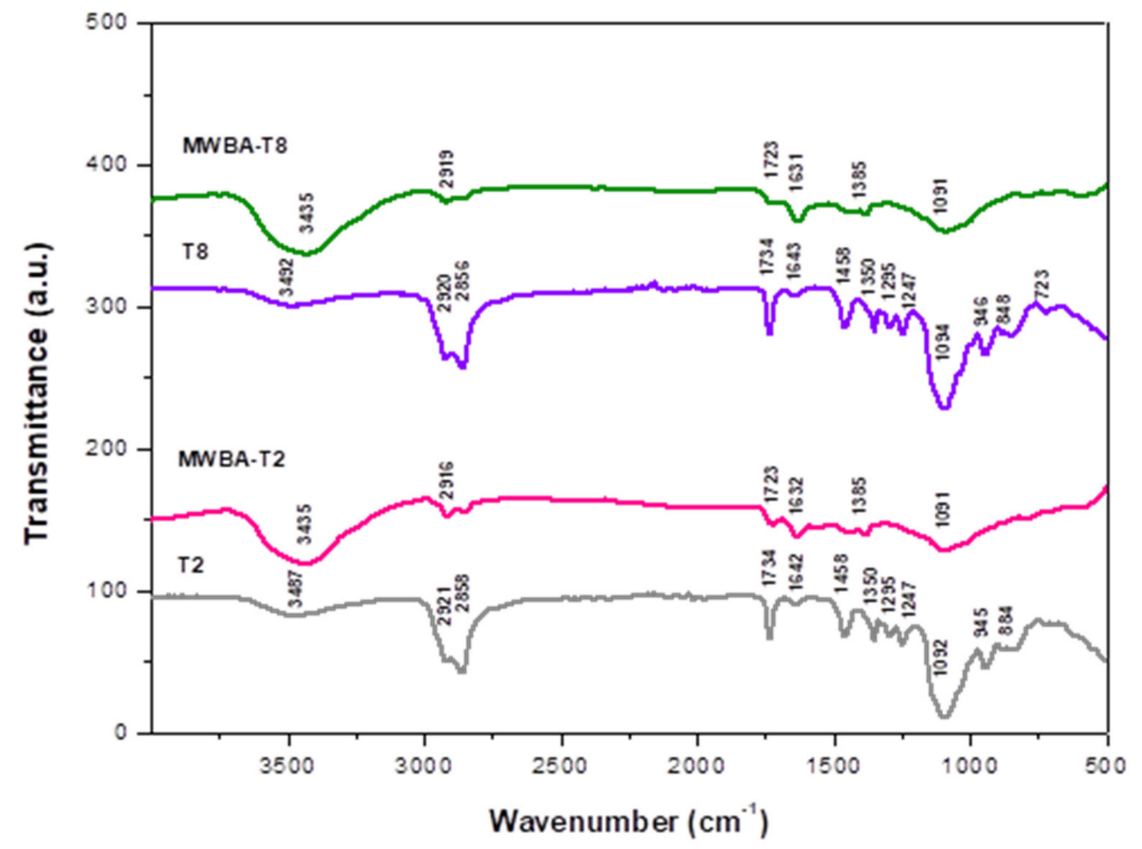

(b)

Figure 1. FTIR spectra of samples: (a) chitosan (CS), MWBA-CS, polyethylene glycol (PG), MWBA-PG and (b) Tween 20 (T2), MWBA-T2, Tween 80 (T8) and MWBA-T8. 
Based on Figure 1a, the classic bands of CS assigned to polysaccharide structures were seen at $3438 \mathrm{~cm}^{-1}$ due to the superimposed axial stretching of $\mathrm{O}-\mathrm{H}$ and $\mathrm{N}-\mathrm{H}$ groups, and a sharp band observed at $1631 \mathrm{~cm}^{-1}$ corresponded to the overlapped axial stretching of $\mathrm{C}=\mathrm{O}$ in the amide I and N-H deformation of amide II. In addition, the band which appeared at $1384 \mathrm{~cm}^{-1}$ can be attributed to the $\mathrm{CH}_{3}$ symmetrical angular deformation mode [34]. Additionally, the fingerprint region of glycosidic bonds ( $\mathrm{C}-\mathrm{O}$ and $\mathrm{C}-\mathrm{O}-\mathrm{C}$ stretching) was located over the range of $1050-1030 \mathrm{~cm}^{-1}$, and this specific band is extremely advantageous for evidencing the presence of CS even in low amounts [35]. All these bands shifted to a higher wavenumber upon CS coating onto MWBA, indicating the successful conjugation of CS molecules with the MWBA sample. The FTIR spectrum of PG demonstrated broad characteristic bands around 3446, 1104 and $961 \mathrm{~cm}^{-1}$ due to the $\mathrm{O}-\mathrm{H}$ stretching, C-O stretching and $\mathrm{C}-\mathrm{C}$ stretching vibrations, respectively. The bands centered around 2889, 1469,1344 and $1241 \mathrm{~cm}^{-1}$ were due to the methylene groups of $\mathrm{C}-\mathrm{H}$ stretching, bending and twisting vibrational modes. Lastly, the bands that occurred at 961,842 and $529 \mathrm{~cm}^{-1}$ were corroborated to the skeletal vibrations. Comparing the FTIR spectra of pure PG and MWBA-PG, the features related to the vibrational modes of PG were mostly found in the PG-coated nanotubes, with some minor shifting in wavenumbers. These findings confirm that the PG molecules were non-covalently attached to the MWBA formulation.

In the spectroscopic data of pure T2 and T8 (Figure 1b), the absorption bands of O-H stretching detected at 3487 and $3492 \mathrm{~cm}^{-1}$ had both shifted to $3435 \mathrm{~cm}^{-1}$ in the biopolymeric MWBA nanocomposites. The spectrum exhibited that an intense $\mathrm{O}-\mathrm{C}=\mathrm{O}$ band at $1734 \mathrm{~cm}^{-1}$ had shifted to $1723 \mathrm{~cm}^{-1}$, and the bands centered around $1092-1094 \mathrm{~cm}^{-1}$ corresponding to the stretching vibration of C-O-C had shifted to $1091 \mathrm{~cm}^{-1}$. Furthermore, it is interesting to note that the characteristic bands observed in the range of $2921-2856 \mathrm{~cm}^{-1}$ which belong to the asymmetric and symmetric methylene stretching vibrations were also seen in the biopolymeric MWBA samples [36]. This observation suggests that the bands could have been overlapped with the $\mathrm{C}-\mathrm{H}$ stretching of BA molecules, leading to an increase in intensity in the FTIR absorption spectra of MWBA-T2 and MWBA-T8. Overall, the spectra of MWBA-T2 and MWBA-T8 samples exactly resembled pure T2 and T8, as expected since the Tween molecules are derived from the same polysorbate family.

\subsection{Thermogravimetric Analysis}

Thermal studies using the thermogravimetric analysis (TGA) technique were carried out to investigate the degradation of biopolymeric MWBA nanocomposites in comparison to pure BA and blank MWNT. Based on Figure 2a, pure BA exhibited an intense, single-step thermal decomposition curve at $303^{\circ} \mathrm{C}$ that was ascribed to the removal of hydroxyl groups through sublimation, generating a total weight loss of $98 \%$. This strong TGA curve of BA was not detected in the thermograms of biopolymer-coated MWBA nanocomposites, suggesting that the BA no longer existed as a crystalline structure in all four nanocomposites. The obtained result is in line with a TGA study conducted by a team of scientists on the isolation of betulin from birch bark using a vacuum and atmospheric sublimation approach [37]. They reported that the thermal degradation of betulin occurring in the temperature range of $250-370{ }^{\circ} \mathrm{C}$ was due to the thermal sublimation of volatile substances. 

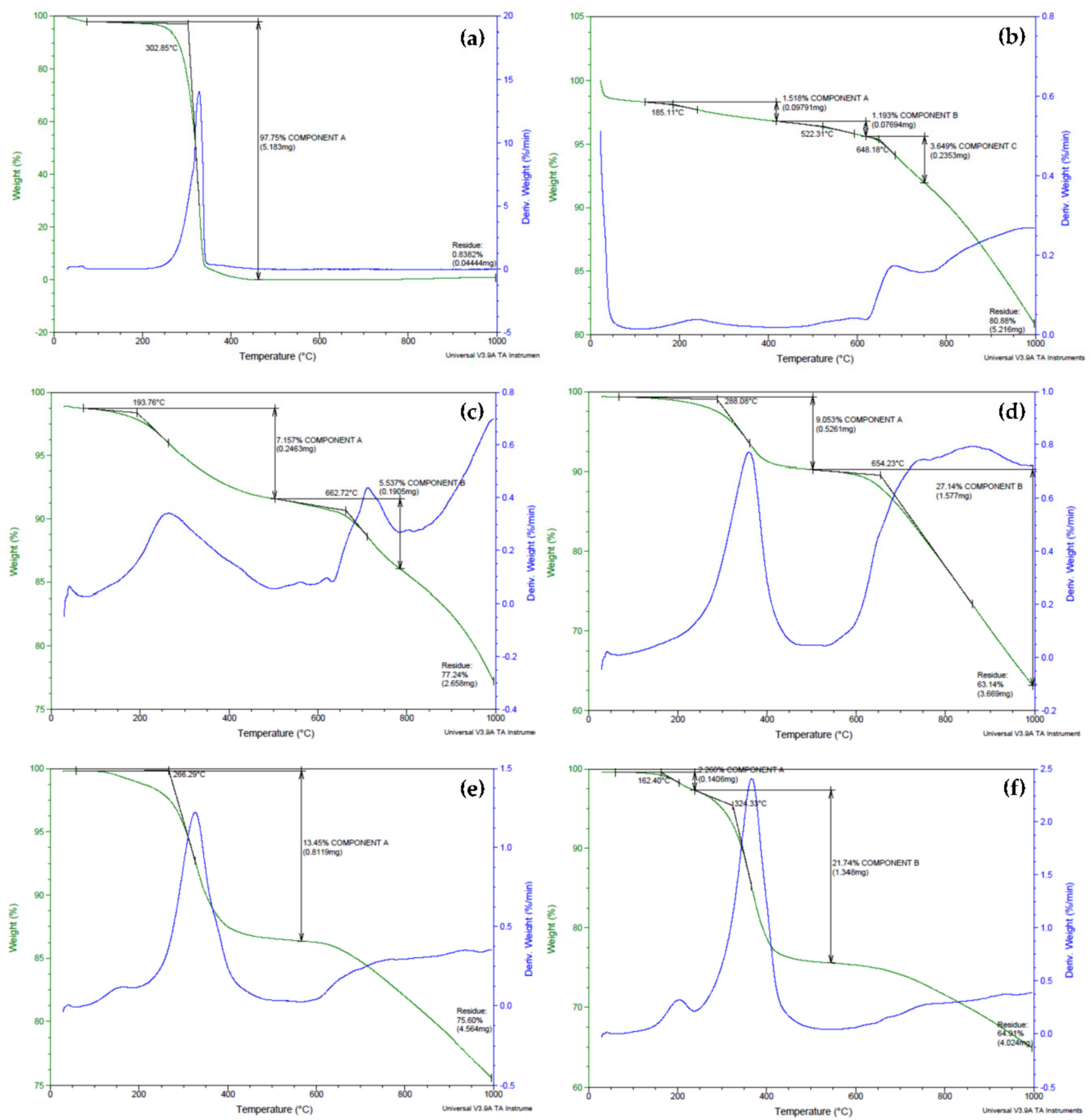

Figure 2. Thermogravimetric analysis (TGA)-DTG thermograms obtained for (a) pure betulinic acid (BA), (b) MWNTCOOH, (c) MWBA-CS, (d) MWBA-PG, (e) MWBA-T2 and (f) MWBA-T8.

As shown in Figure 2b, the thermal property of MWNT-COOH was observed to barely lose any weight from ambient temperature up to $500{ }^{\circ} \mathrm{C}$. This indicates that the oxidized nanotubes were thermally stable up to $500^{\circ} \mathrm{C}$, which is consistent with previous reports published in the literature $[19,38]$. The TGA thermogram for the degradation of MWNT-COOH illustrates the occurrence of three weight loss steps. The first step, which was related to the evaporation of moisture and water crystallization, occurred at $185^{\circ} \mathrm{C}$ (weight loss about 1.5\%), and this was followed by subsequent decomposition steps that took place in the temperature range of $522-648^{\circ} \mathrm{C}$ (weight loss around 1.2-3.6\%). These weight loss steps were due to the degradation of the carboxylic acid functional groups grafted on the nanotubes' surfaces during the oxidation process. The carboxyl groups reacted to form hydrogen bonds between the positively charged $\mathrm{H}$ atom of one carboxyl group and another electronegative $\mathrm{O}$ atom from a neighboring carboxyl group, which then developed into a hexagonal hydrogen bond net [39]. This phenomenon leads to 
an increase in the activation energy and, as a result, the overall thermal stability of the oxidized nanotubes was greatly enhanced.

The thermograms of the samples presented in Figure 2c-f show that the MWBA-CS, MWBA-PG, MWBA-T2 and MWBA-T8 have similar degradation profiles where two main decomposition stages were observed after the coating treatment was applied. For example, in the temperature ranges between $194-288$ and $654-663{ }^{\circ} \mathrm{C}$, approximately $7-9 \%$ and 6-27\% weight losses were detected for MWBA-CS and MWBA-PG, respectively. On the other hand, MWBA-T2 and MWBA-T8 seemed to demonstrate lower thermal stability at a temperature below $500{ }^{\circ} \mathrm{C}$. For example, about $2 \%$ weight loss was recorded at $118-162{ }^{\circ} \mathrm{C}$ and about $21 \%$ weight loss was seen at $283-324{ }^{\circ} \mathrm{C}$. The first thermal decomposition stage is commonly related to the evaporation of physisorbed water, which was loosely bound to the surface of the sample, while the second stage would be associated with the pyrolytic decomposition of the polymer. The four polymeric drug-loaded nanotubes began to degrade and caused a modest weight loss in the range of $6-27 \%$ at a temperature above $260{ }^{\circ} \mathrm{C}$. The weight loss at this temperature was due to the decomposition of the surface functional groups such as $\mathrm{O}-\mathrm{H}, \mathrm{C}=\mathrm{O}, \mathrm{N}-\mathrm{H}$ and $\mathrm{C}-\mathrm{H}$. On top of that, all four biopolymer-coated nanocomposites displayed different thermal profiles than the oxidized nanotubes and pure BA, indicating the successful interaction between the MWBA and biopolymer, which subsequently altered the TGA curve of the material. Overall, it was noted that the findings obtained from the TGA study showed a good agreement with the FTIR spectroscopy result, as discussed earlier.

The thermogravimetric property of the samples and their subsequent weight losses in the decomposition stages are summarized in Table 1. Based on the samples' thermogravimetric characteristics, it was noted that the biopolymeric MWBA nanocomposites demonstrated synergistically improved thermal stability, where the degradation mainly occurred in two steps when compared to pure BA alone. This is because the biopolymercoated MWBA nanocomposites exhibited a decrease in the particle size due to the addition of nanoscale material acting as a drug delivery agent. Hence, the sample has a higher specific surface area, which eventually led to easier vaporization and earlier decomposition below the temperature of $300^{\circ} \mathrm{C}$. In addition, the interfacial bonds such as hydrophobic and electrostatic forces might have become significantly stronger and more apparent between MWBA and biopolymer after the coating treatment. This can be verified through the increase in the overall effective thermal conductivity of the nanocomposites in the second stage of thermal degradation. This finding is consistent with other similar reports conducted on the thermal properties of nanocomposites derived from polymers and inorganic nanoparticles [40].

\subsection{Raman Spectroscopy}

Raman spectroscopy is an essential analytical tool frequently used to characterize carbon-based materials in terms of their chemical structure and physical property. This nondestructive key technique reveals the various characteristic spectra of new nanostructured $\mathrm{sp}^{2}$ carbon allotropes, such as carbon fibers, carbon black, pyrolytic graphite, fullerenes, graphenes, CNT as well as their degree of structural disorder [41,42].

The Raman spectra of CNT typically consist of a few prominent peaks, namely the $G$ and $G^{\prime}$ bands, the D band as well as other relatively weak bands. The $G$ band, or the so-called tangential mode, can be ascribed to the first-order Raman scattering of the degenerate in-plane $E_{2 g}$ phonon mode at the Brillouin zone center and normally occurs near $1580 \mathrm{~cm}^{-1}$. The disorder-induced $\mathrm{D}$ band, which corroborates to the breathing vibrations of the aromatic hexagonal sp $\mathrm{sp}^{2}$ carbon rings, appears around $1350 \mathrm{~cm}^{-1}$ and requires a defect for its activation. Hence, the $\mathrm{D}$ band intensity relative to the $\mathrm{G}$ band intensity $\left(\mathrm{I}_{\mathrm{D}} / \mathrm{I}_{\mathrm{G}}\right)$ provides an excellent indicator for showing the structural defects present in carbon nanomaterials [43]. The $\mathrm{G}^{\prime}$ band, or sometimes also referred to as the harmonic $2 \mathrm{D}$ band, is the second-order Raman spectrum due to in-plane transverse optical mode at the $\mathrm{K}$ point zone boundary, and normally appears in the range of $2500-2800 \mathrm{~cm}^{-1}$. Lastly, the 
radial breathing mode (RBM), which is related to the atomic vibration of the $\mathrm{sp}^{2}$ carbon atoms in the radial direction and is generally observed between 120 and $250 \mathrm{~cm}^{-1}$, is the characteristic feature of SWNT.

Table 1. The TGA-DTG characteristics of pure BA, pure biopolymers, blank MWNT, MWBA and biopolymeric MWBA nanocomposites.

\begin{tabular}{|c|c|c|c|c|}
\hline \multirow{2}{*}{ Samples } & \multirow{2}{*}{ Atmosphere } & \multicolumn{3}{|c|}{ Decomposition Stage } \\
\hline & & First & Second & Third \\
\hline \multirow{2}{*}{ Pure BA } & Weight loss (\%) & $97.8 \%$ & - & - \\
\hline & Temperature $\left({ }^{\circ} \mathrm{C}\right)$ & $302.9^{\circ} \mathrm{C}$ & - & - \\
\hline \multirow{2}{*}{ MWNT-COOH } & Weight loss (\%) & $1.5 \%$ & $1.2 \%$ & $3.7 \%$ \\
\hline & Temperature $\left({ }^{\circ} \mathrm{C}\right)$ & $185.1^{\circ} \mathrm{C}$ & $522.3^{\circ} \mathrm{C}$ & $648.2^{\circ} \mathrm{C}$ \\
\hline \multirow{2}{*}{ MWBA } & Weight loss (\%) & $3.2 \%$ & $1.1 \%$ & $8.3 \%$ \\
\hline & Temperature $\left({ }^{\circ} \mathrm{C}\right)$ & $153.0^{\circ} \mathrm{C}$ & $537.5^{\circ} \mathrm{C}$ & $636.4^{\circ} \mathrm{C}$ \\
\hline \multirow{2}{*}{ CS } & Weight loss (\%) & $48.8 \%$ & - & - \\
\hline & Temperature $\left({ }^{\circ} \mathrm{C}\right)$ & $261.4^{\circ} \mathrm{C}$ & - & - \\
\hline \multirow{2}{*}{ MWBA-CS } & Weight loss (\%) & $7.2 \%$ & $5.5 \%$ & - \\
\hline & Temperature $\left({ }^{\circ} \mathrm{C}\right)$ & $193.8^{\circ} \mathrm{C}$ & $662.7^{\circ} \mathrm{C}$ & - \\
\hline \multirow{2}{*}{ PG } & Weight loss (\%) & $42.4 \%$ & $57.2 \%$ & - \\
\hline & Temperature $\left({ }^{\circ} \mathrm{C}\right)$ & $201.9^{\circ} \mathrm{C}$ & $339.1^{\circ} \mathrm{C}$ & - \\
\hline \multirow{2}{*}{ MWBA-PG } & Weight loss (\%) & $9.1 \%$ & $27.1 \%$ & - \\
\hline & Temperature $\left({ }^{\circ} \mathrm{C}\right)$ & $288.1^{\circ} \mathrm{C}$ & $654.2^{\circ} \mathrm{C}$ & - \\
\hline \multirow{2}{*}{$\mathrm{T} 2$} & Weight loss (\%) & $95.3 \%$ & - & - \\
\hline & Temperature $\left({ }^{\circ} \mathrm{C}\right)$ & $373.4^{\circ} \mathrm{C}$ & - & - \\
\hline \multirow{2}{*}{ MWBA-T2 } & Weight loss (\%) & $1.5 \%$ & $12.0 \%$ & - \\
\hline & Temperature $\left({ }^{\circ} \mathrm{C}\right)$ & $117.5^{\circ} \mathrm{C}$ & $266.3^{\circ} \mathrm{C}$ & - \\
\hline \multirow{2}{*}{$\mathrm{T} 8$} & Weight loss (\%) & $96.3 \%$ & - & - \\
\hline & Temperature $\left({ }^{\circ} \mathrm{C}\right)$ & $387.2^{\circ} \mathrm{C}$ & - & - \\
\hline \multirow{2}{*}{ MWBA-T8 } & Weight loss (\%) & $2.3 \%$ & $21.7 \%$ & - \\
\hline & Temperature $\left({ }^{\circ} \mathrm{C}\right)$ & $162.4^{\circ} \mathrm{C}$ & $324.3^{\circ} \mathrm{C}$ & - \\
\hline
\end{tabular}

Figure 3a illustrates the Raman spectrum of carboxylated MWNT and BA-loaded MWNT for comparison purposes. As can be observed in the Raman spectrum, the main Raman signature bands occurred at 1342 (D band), 1575 ( $G$ band) and 2681 ( $\mathrm{G}^{\prime}$ band) $\mathrm{cm}^{-1}$. The $\mathrm{D}$ band is defect activated Raman mode, suggesting that the samples were not of a complete crystalline graphitic material and that they contained a high amount of defect structures. The presence of the $G$ band ( $E_{2 g}$ symmetry) confirmed that all samples were composed of $\mathrm{sp}^{2}$ carbon networks, which is the essential feature of CNT. The $\mathrm{G}^{\prime}$ band, which is associated with the stacking order and the number of graphene layers, was clearly seen in the Raman spectrum as a result of interactions between stacked graphene layers. Furthermore, a relatively weak band belonging to the disordered graphitic lattice $\left(\mathrm{A}_{1 \mathrm{~g}}\right.$ symmetry) was seen near $1100 \mathrm{~cm}^{-1}$. The same band was also observed by other teams, and the authors provisionally assigned it to the stretching vibrations of double and single carbon-carbon bonds in polyene organic compounds or carbon $\mathrm{sp}^{2}-\mathrm{sp}^{3}$ bonds [44,45]. Lastly, the RBM was not detected in the nanotubes as the signals were too weak to be observable. Besides, this characteristic phonon mode is not a common feature for large diameter tubes such as MWNT. 

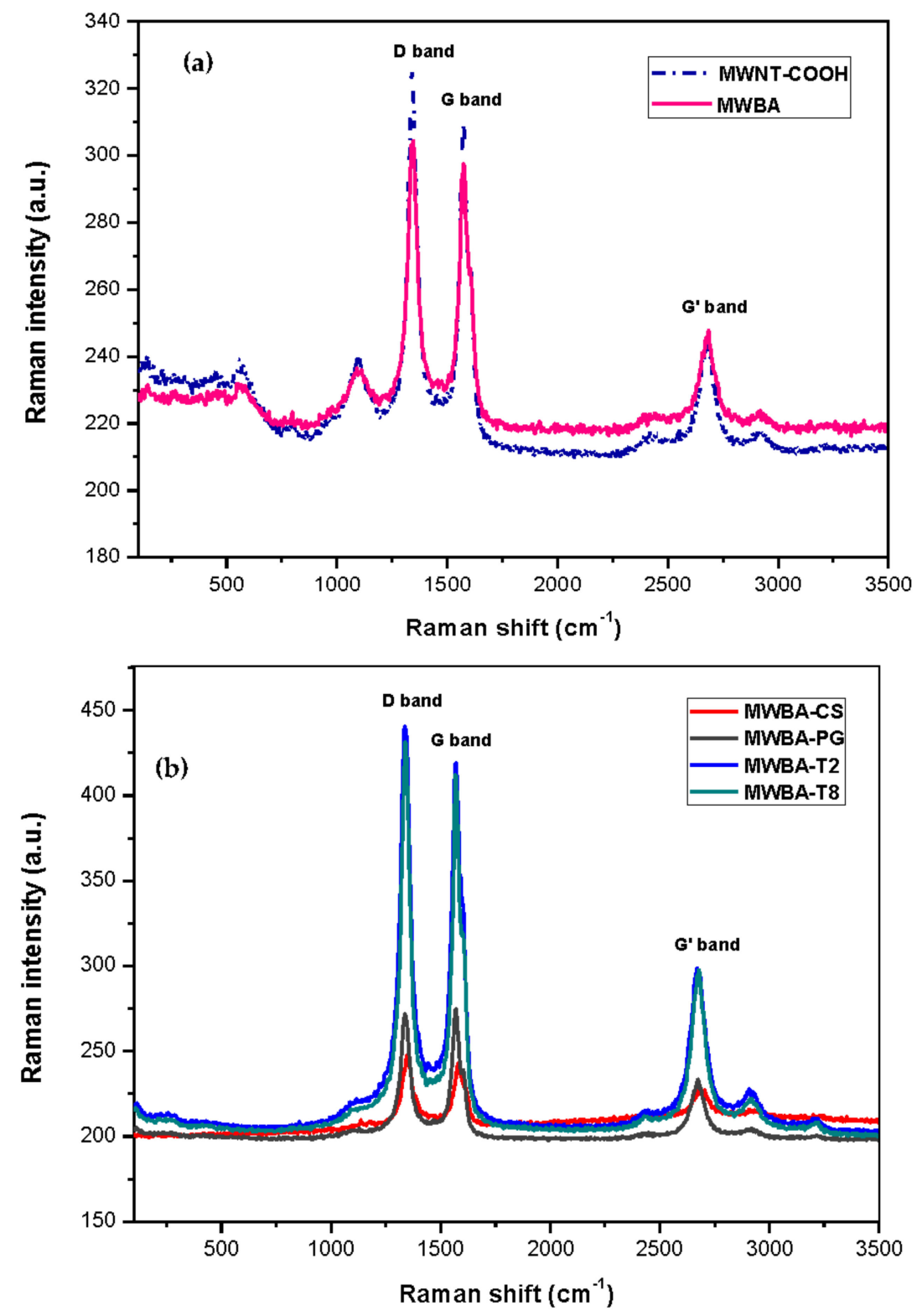

Figure 3. Raman spectra of samples: (a) MWNT-COOH, MWBA; (b) MWBA-CS, MWBA-PG, MWBAT2 and MWBA-T8.

Upon comparison with Figure 3a, it was noted that the Raman bands in the biopolymeric MWBA samples (Figure 3b) became sharper and stronger. In fact, the line width of the bands in all four samples appeared to be much narrower than that of MWBA (uncoated sample). The characteristic bands of MWNT, namely the D, G and G' bands, were identified at 1338-1346, 1567-1579 and 2671-2674 $\mathrm{cm}^{-1}$, respectively, for all four samples as they generally shifted to a lower wavenumber after the coating treatment. When the functional groups belonging to the biopolymer were formed on the surface of nanotubes during the coating process, these signature bands can still be easily identified. This reflects that their structural characteristics were not affected by the application of the biopolymer coating process [46]. In addition, the minor spectral shifts could be due to the successful conjugation of biopolymer molecules with MWBA, where the polymer chains formed a strong interfacial adhesion through $\sigma$ bond with surface oxygen functional groups [47].

Apart from that, the integrated intensity ratio $\left(\mathrm{I}_{\mathrm{D}} / \mathrm{I}_{\mathrm{G}}\right)$ of MWBA with polymer-coated MWBA showed a decreasing fashion from uncoated to coated samples (except for MWBAT2 and MWBA-T8, where the intensity ratio values were quite similar to the uncoated 
MWBA). Data obtained from the Raman analysis presented in Table 2 clearly show a reduced defect amount due to the curing effect of the polymer matrix on MWBA when compared to the uncoated MWBA. MWNT-COOH has the highest $\mathrm{I}_{\mathrm{D}} / \mathrm{I}_{\mathrm{G}}$ ratio among the rest of the samples, indicating that there are more defects as the $\mathrm{sp}^{2}$ bonds are broken down and more transition from $\mathrm{sp}^{2}$ to $\mathrm{sp}^{3}$ carbon. In general, the larger the amount of defects, the higher the $\mathrm{D}$ band intensity and, hence, the larger the intensity ratio.

Table 2. The relative Raman intensity signature bands for all samples.

\begin{tabular}{ccccc}
\hline Samples & $\begin{array}{c}\text { D Band Position } \\
\left(\mathbf{c m}^{-\mathbf{1}}\right)\end{array}$ & $\begin{array}{c}\text { G Band Position } \\
\left(\mathbf{c m}^{-\mathbf{1}}\right)\end{array}$ & $\begin{array}{c}\mathbf{G}^{\prime} \text { Band Position } \\
\left(\mathbf{c m}^{-\mathbf{1}} \mathbf{)}\right.\end{array}$ & $\begin{array}{c}\text { Intensity Ratio } \\
\left(\mathbf{I}_{\mathrm{D}} / \mathbf{I}_{\mathrm{G}}\right)\end{array}$ \\
\hline MWNT-COOH & 1342 & 1575 & 2681 & 1.052 \\
MWBA & 1346 & 1575 & 2685 & 1.020 \\
MWBA-CS & 1346 & 1579 & 2674 & 1.008 \\
MWBA-PG & 1338 & 1571 & 2674 & 0.989 \\
MWBA-T2 & 1338 & 1571 & 2671 & 1.053 \\
MWBA-T8 & 1338 & 1567 & 2678 & 1.046 \\
\hline
\end{tabular}

\subsection{Morphology Study}

Figure 4 reveals the surface morphology of pure BA, blank oxidized nanotubes and BA-loaded MWNT. As seen in Figure 4a, the FESEM micrograph shows that a BA crystal appeared as a smooth, elongated microfiber structure with approximately $1 \mu \mathrm{m}$ in diameter. Figure $4 \mathrm{~b}, \mathrm{c}$ presents the morphology of the MWNT before and after loading with BA. Since the MWBA sample was prepared by the ultra-sonication method, it can be seen that the MWBA nanotubes were in a slightly dispersed physical state while maintaining their tubular nanostructures as compared to the blank nanotubes. Nanotubes are known to easily agglomerate due to strong van der Waals forces and, therefore, they have the tendency to form small bundles. The FESEM observations reflect that the ultra-sonication process enhanced the dispersibility of the nanotubes and, most importantly, it did not damage the tubular shapes of the CNT samples. Although the crystalline structure of BA was no longer visible after it was loaded onto MWNT, the outside diameter of the blank nanotubes was generally seen to increase slightly in thickness from approximately $30 \mathrm{~nm}$ to $50 \mathrm{~nm}$ after the loading process. These images indicate that the BA molecules were loaded successfully onto the surface of the MWNT, which is in line with the previous analysis results.

The FESEM characterization analysis of MWBA nanocomposites coated with different types of biopolymers is presented in Figure 5. Based on these images, it was found that the surface morphology of the four samples was flat and more compact due to the formation of the hydrophilic polymer matrix during the coating process. This is more evident especially in Figure 5a,c, where the introduction of the CS and PG molecules through the cross-linking of polymer chains may have improved the interfacial adhesion between the nanotubes and the coating agent. On the other hand, Figure $5 \mathrm{e}, \mathrm{f}$ demonstrates that the samples were less condensed and more porous, possibly due to the formation of micelles beyond a certain concentration which is known as critical micelle concentration of the surfactants. Overall, it was also revealed that the addition of these biopolymers further decreased the coarse and uneven surface feature of uncoated MWBA, as shown in Figure 4c, through the wrapping technique. This can be verified by the Raman integrated intensity ratio of $\mathrm{I}_{\mathrm{D}} / \mathrm{I}_{\mathrm{G}}$, where the degree of porosity decreased with the incorporation of the hydrophilic polymer. Furthermore, as seen from the close-up FESEM images, the tubular shapes of the nanotubes were easily identified, suggesting that the surface modification by the layer of biopolymer did not significantly change the nanostructure of the MWNT. 

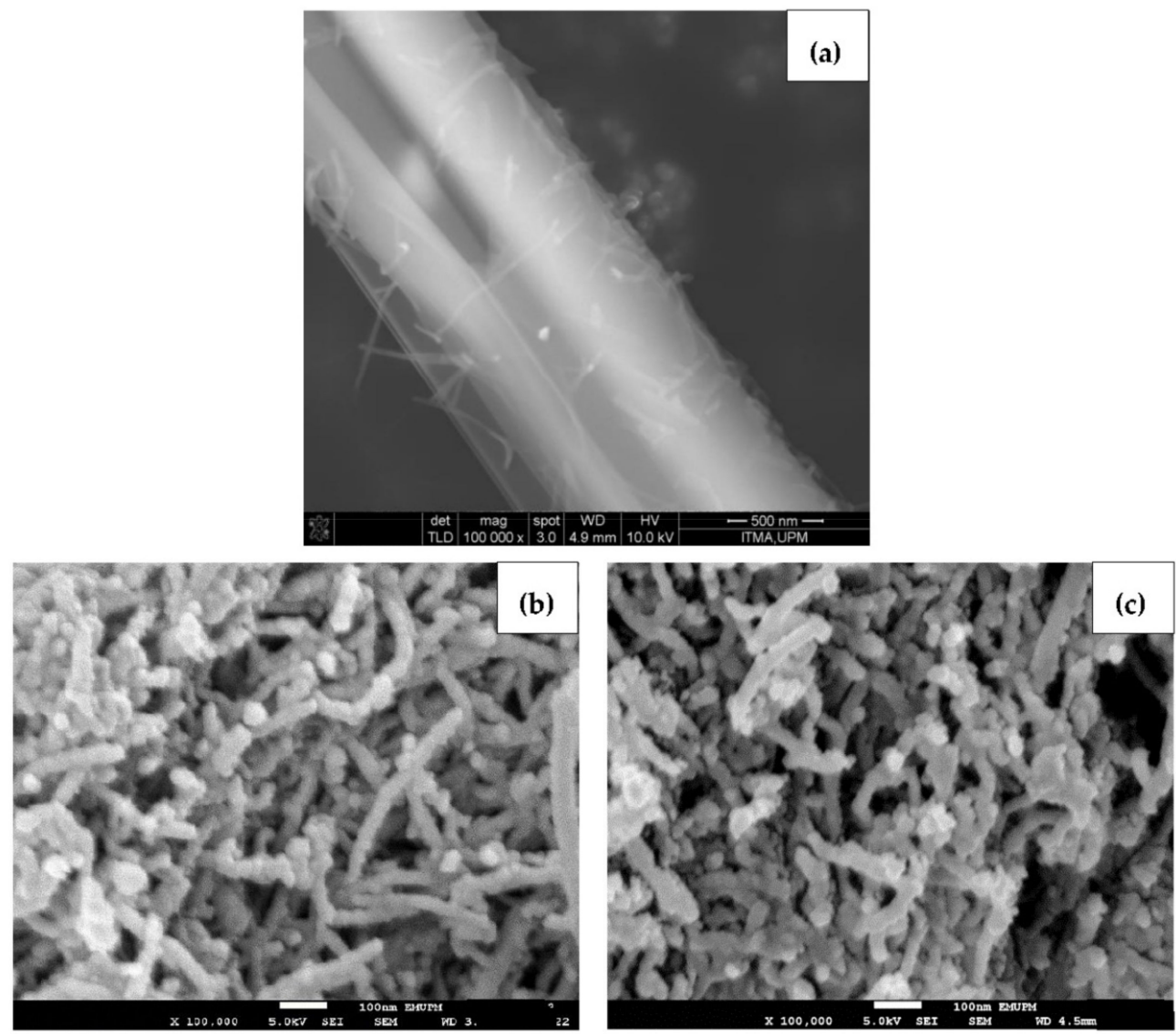

Figure 4. FESEM images of (a) pure BA; (b) MWNT-COOH and (c) MWBA at a magnification of 100,000×.

\subsection{In Vitro Cytotoxicity Study}

Cell culture assay is a very useful technique to assess the biocompatibility of various materials due to its relative simplicity, high sensitivity and good reproducibility for studying the potential toxicity or irritancy of materials and chemicals. To determine the in vitro cytotoxicity effect of the incorporated biopolymer matrix with MWBA, MTT assay was performed according to the literature using a normal and healthy mouse embryonic fibroblast $\mathrm{NIH} / 3 \mathrm{~T} 3$ cell line [48]. This important fibroblast culture, which was originally established from Swiss mouse embryos, is frequently used in biomedical research for the preliminary screening of materials prior to in vivo assessment [49-51]. This cell line provides an ideal way to quantify the cyto-compatibility action of living cells to the nanomaterial owing to its ability to divide indefinitely at a constant growth rate in culture medium, and, most importantly, it is easy to be maintained [52].

The observation from our previous study indicated that the percentage of viable cells was found to be reduced substantially to less than $40 \%$ when incubated with $50 \mu \mathrm{g} / \mathrm{mL}$ of uncoated MWBA for $72 \mathrm{~h}$ [30]. To circumvent this issue, we have decided to coat the MWBA nanocomposites with a layer of hydrophilic polymer to further improve the biocompatibility of the drug formulation on NIH/3T3 cells. The cells acquired from ATCC (Virginia, US) were exposed to varying concentrations $(1.56-100 \mu \mathrm{g} / \mathrm{mL}$ ) of biopolymeric MWBA nanocomposites, and the results of the MTT assay are presented in Figure 6 . The coating agents utilized in this study are natural, highly water-soluble polymer compounds frequently used in food science and biomedical research due to their excellent biocompatibility, low toxicity, good mucoadhesion and stabilizing properties. Subsequently, we have observed that all biopolymer-coated samples did not induce cell mortality when all viable cells were maintained at $80 \%$ and above, even at the highest concentration tested $(100 \mu \mathrm{g} / \mathrm{mL})$. This is compelling evidence in which the encapsulated MWBA in the watersoluble polymer matrix exhibited a much higher biocompatibility to the normal cells. The 
observed data suggest that the coating agent, when incorporated into the formulation, would render the nanomaterial to be a potential drug delivery system in the physiological environment. Nevertheless, further exploration of their cellular uptake and binding mode is still necessary and could prove to be very useful to assess whether this improved formulation could be verified under the in vivo condition.
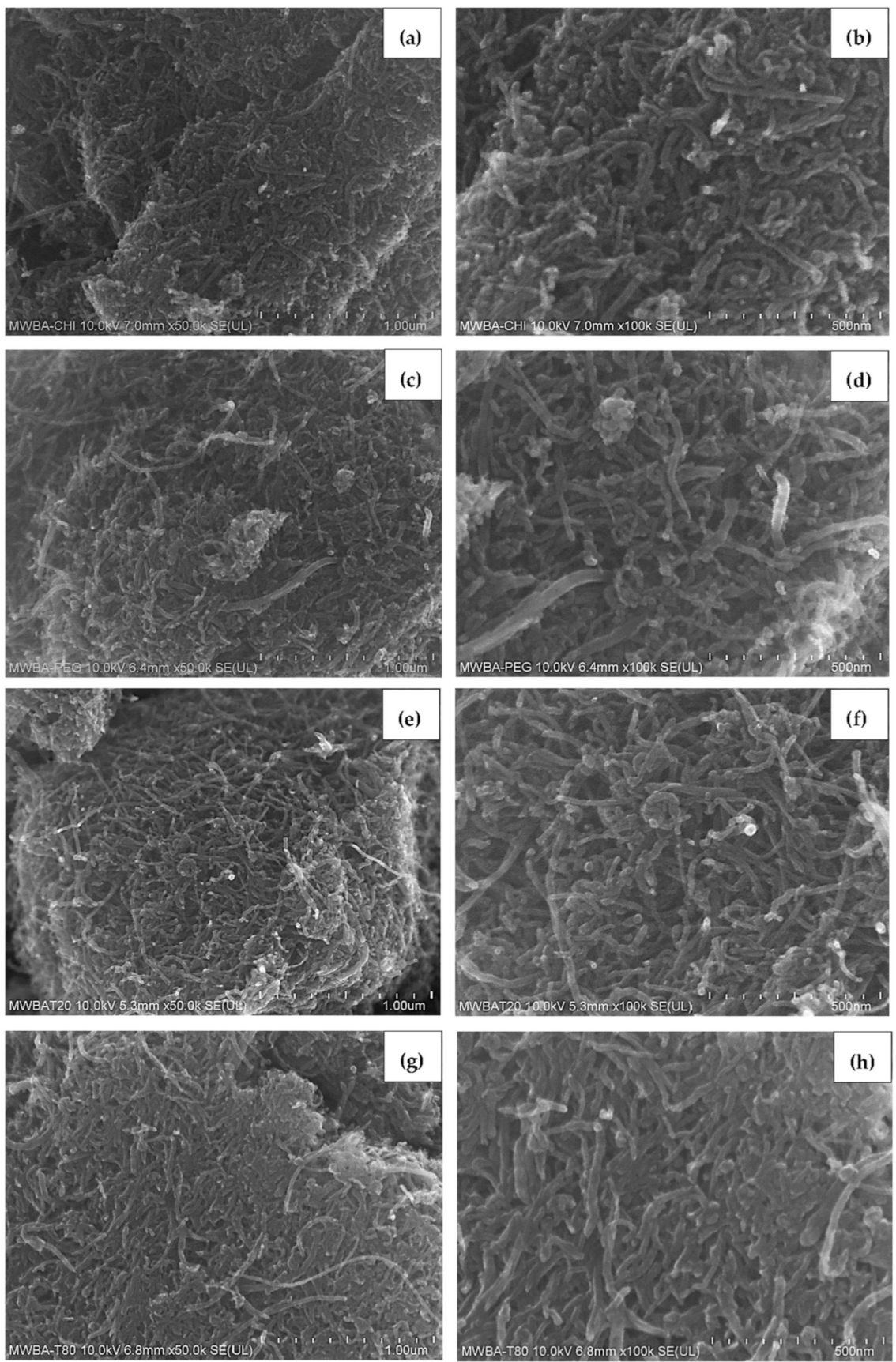

Figure 5. FESEM images of biopolymeric MWBA nanocomposites captured at low $(50,000 \times)$ and high $(100,000 \times)$ magnifications: (a,b) MWBA-CS; (c,d) MWBA-PG; (e,f) MWBA-T2; (g,h) MWBA-T8. 


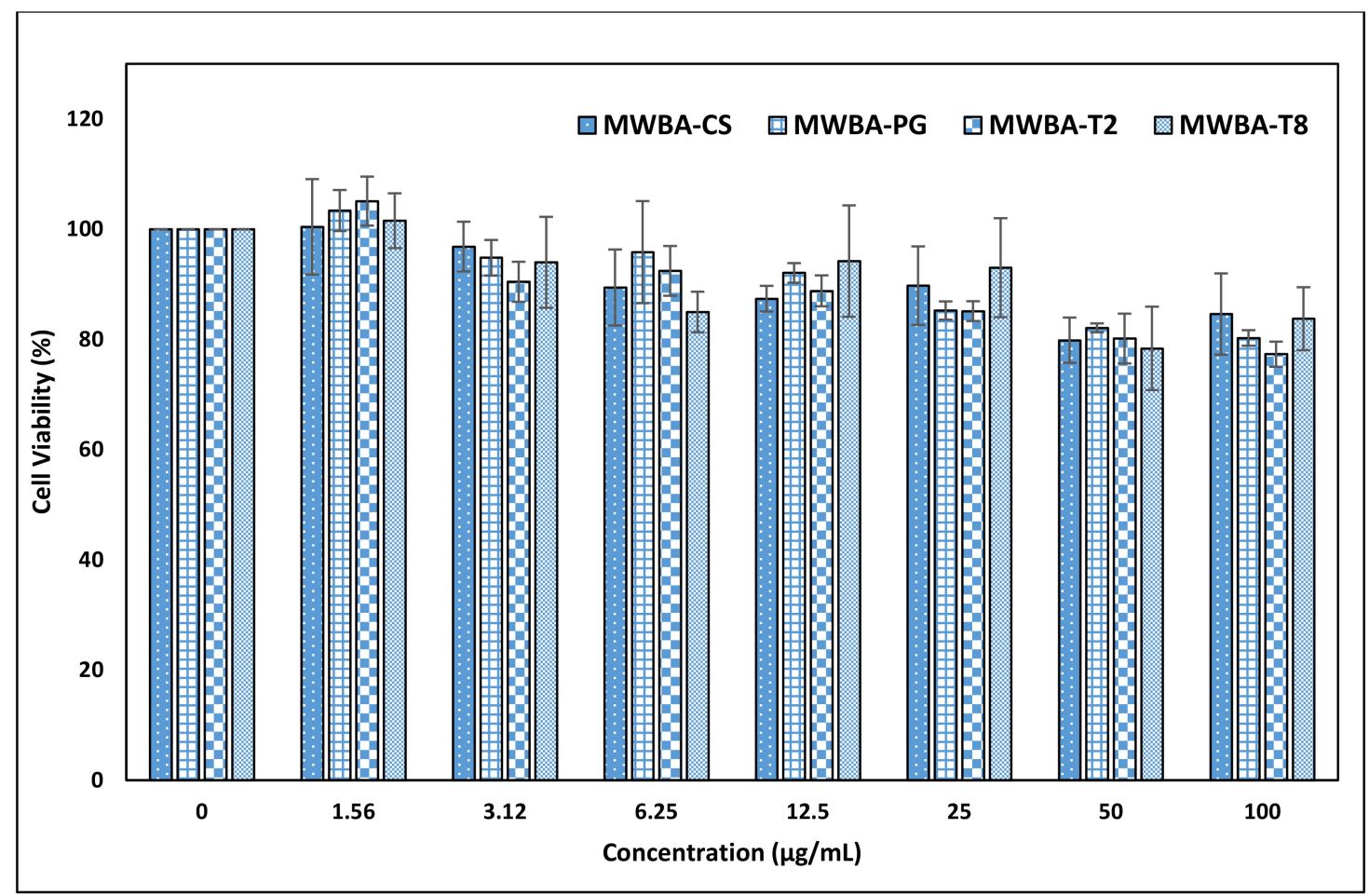

Figure 6. The biological effects of biopolymeric MWBA nanocomposites on NIH/3T3 non-tumor cell line viability after $72 \mathrm{~h}$ incubation as assessed by MTT assay. Untreated normal cell lines were used as a control sample. Statistical analysis was performed using one-way ANOVA followed by Tukey HSD post-hoc test $(p<0.05)$.

\section{Conclusions}

In this work, the MWBA nanocomposites were modified by a simple, non-covalent functionalization method with the incorporation of a water-soluble polymer through hydrophobic and electrostatic interfacial bonding. From the results obtained, we found out that the presence of functional groups, which were correlated to the respective polymer molecules, was in good agreement with the thermal decomposition of biopolymeric MWBA nanocomposites and comparable to the decrease in the Raman intensity ratio of those coated samples. The surface morphological study confirmed that the ultra-sonication method did not destroy the tubular structures of the samples, but further improved the dispersion state of the bundled nanotubes. Furthermore, the MTT biological test performed on normal fibroblast NIH/3T3 cells showed no cytotoxic effects at the tested dosages up to $100 \mu \mathrm{g} / \mathrm{mL}$ for all four types of nanocomposites, suggesting their potential use in the application of drug delivery. Even though MTT assay is far superior to other dye exclusion approaches, supplementary control experiments such as WST, lactate dehydrogenase or fluorometric assay should be conducted on par to detect possible chemistry interference when accessing cell viability. Nonetheless, this still warrants a further investigation on the formulation being developed, which requires a higher concentration to be tested on other types of normal cells.

Author Contributions: J.M.T.; conceptualization, methodology, software, validation, formal analysis, investigation, data curation, writing — original draft preparation, S.B.; methodology, investigation, S.F.; resources, supervision, writing-review and editing, M.Z.H.; conceptualization, resources, supervision, project administration, funding acquisition, writing — review and editing. All authors have read and agreed to the published version of the manuscript.

Funding: The authors are grateful to the Ministry of Education of Malaysia (MOE) and Universiti Putra Malaysia for its financial support under the Gran Putra-IPB Berimpak, UPM/8003/3/1/GPB/2019/9678800. 
Institutional Review Board Statement: Not applicable.

Informed Consent Statement: Not applicable.

Data Availability Statement: The data presented in this study are available on request from the corresponding author.

Acknowledgments: J.M.T. is thankful to the MOE for providing a MyPhD scholarship under the MyBrain15 program.

Conflicts of Interest: The authors declare that they have no conflict of interest.

\section{References}

1. Feynman, R.P. There's plenty of room at the bottom. Eng. Sci. 1960, 23, 22-36.

2. Taniguchi, N. On the basic concept of nano-technology. In Proceedings of the International Conference on Production Engineering, JSPE Part II, Tokyo, Japan, 26-29 August 1974; pp. 18-23.

3. Siddiqui, A.A.; Iram, F.; Siddiqui, S.; Sahu, K. Role of natural products in drug discovery process. Int. J. Drug Dev. Res. 2014, 6, 172-204.

4. Yang, Y.; Xie, T.; Tian, X.; Han, N.; Liu, X.; Chen, H.; Qi, J.; Gao, F.; Li, W.; Wu, Q.; et al. Betulinic acid-nitrogen heterocylic derivatives: Design, synthesis and antitumor evaluation in vitro. Molecules 2020, 25, 948. [CrossRef]

5. Şoica, C.M.; Dehelean, C.A.; Peev, C.; Aluas, M.; Zupkó, I.; Kása, P., Jr.; Alexa, E. Physico-chemical comparison of betulinic acid, betulin and birch bark extract and in vitro investigation of their cytotoxic effects towards skin epidermoid carcinoma (A431), breast carcinoma (MCF7) and cervix adenocarcinoma (HeLa) cell lines. Nat. Prod. Res. 2012, 26, 968-974. [CrossRef] [PubMed]

6. Cichewicz, R.H.; Kouzi, S.A. Chemistry, biological activity and chemotherapeutic potential of betulinic acid for the prevention and treatment of cancer and HIV infection. Med. Res. Rev. 2004, 24, 90-114. [CrossRef]

7. Yogeeswari, P.; Sriram, D. Betulinic acid and its derivatives: A review on their biological properties. Curr. Med. Chem. 2005, 12, 657-666. [CrossRef] [PubMed]

8. Ji, S.; Liu, C.; Zhang, B.; Yang, F.; Xu, J.; Long, J.; Jin, C.; Fu, D.L.; Ni, Q.X.; Yu, X.J. Carbon nanotubes in cancer diagnosis and therapy. Biochim. Biophys. Acta Rev. Cancer 2010, 1806, 29-35. [CrossRef]

9. Hao, M.; Chen, B.; Zhao, X.; Zhao, N.; Xu, F.-J. Organic/inorganic nanocomposites for cancer immunotherapy. Mater. Chem. Front. 2020, 4, 2571. [CrossRef]

10. Zhang, W.; Zhang, Z.; Zhang, Y. The application of carbon nanotubes in target drug delivery systems for cancer therapies. Nanoscale Res. Lett. 2011, 6, 555. [CrossRef] [PubMed]

11. Tîlmaciu, C.M.; Morris, M.C. Carbon nanotube biosensors. Front. Chem. 2015, 3, 59. [CrossRef] [PubMed]

12. Iijima, S. Helical microtubules of graphitic carbon. Nature 1991, 354, 56-58. [CrossRef]

13. Takakura, A.; Beppu, K.; Nishihara, T.; Fukui, A.; Kozeki, T.; Namazu, T.; Miyauchi, Y.; Itami, K. Strength of carbon nanotubes depends on their chemical structures. Nat. Commun. 2019, 10, 3040. [CrossRef] [PubMed]

14. Tan, J.M.; Saifullah, B.; Kura, A.U.; Fakurazi, S.; Hussein, M.Z. Incorporation of levodopa into biopolymer coatings based on carboxylated carbon nanotubes for $\mathrm{pH}$-dependent sustained release drug delivery. Nanomaterials 2018, 8, 389. [CrossRef]

15. Karajanagi, S.S.; Yang, H.; Asuri, P.; Sellitto, E.; Dordick, J.S.; Kane, R.S. Protein-assisted solubilisation of single-walled carbon nanotubes. Langmuir 2006, 22, 1392-1395. [CrossRef]

16. Mulvey, J.; Villa, C.; McDevitt, M.R.; Escorcia, F.E.; Casey, E.; Scheinberg, D.A. Self-assembly of carbon nanotubes and antibodies on tumours for targeted amplified delivery. Nat. Nanotechnol. 2013, 8, 763-771. [CrossRef]

17. Ramos-Perez, V.; Cifuentes, A.; Coronas, N.; de Pablo, A.; Borrós, S. Modification of carbon nanotubes for gene delivery vectors. Methods Mol. Biol. 2013, 1025, 261-268. [PubMed]

18. Scheinberg, D.A.; McDevitt, M.R.; Dao, T.; Mulvey, J.J.; Feinberg, E.; Alidori, S. Carbon nanotubes as vaccine scaffolds. Adv. Drug Deliv. Rev. 2013, 65, 2016-2022. [CrossRef]

19. Metwally, N.H.; Saad, G.R.; Abd El-Wahab, E.A. Grafting of multiwalled carbon nanotubes with pyrazole derivatives: Characterization, antimicrobial activity and molecular docking study. Int. J. Nanomed. 2019, 14, 6645-6659. [CrossRef]

20. Galano, A. Carbon nanotubes: Promising agents against free radicals. Nanoscale 2010, 2, 373-380. [CrossRef] [PubMed]

21. Lamprecht, C.; Plochberger, B.; Ruprecht, V.; Wieser, S.; Rankl, C.; Heister, E.; Unterauer, B.; Brameshuber, M.; Danzberger, J.; Lukanov, P.; et al. A single-molecule approach to explore binding, uptake and transport of cancer cell targeting nanotubes. Nanotechnology 2014, 25, 125704. [CrossRef]

22. Usui, Y.; Haniu, H.; Tsuruoka, S.; Saito, N. Carbon nanotubes innovate on medical technology. Med. Chem. 2012, 2, 1-6. [CrossRef]

23. De Stefano, D.; Carnuccio, R.; Maiuri, M.C. Nanomaterials toxicity and cell death modalities. J. Drug Deliv. 2012, 2012, 167896. [CrossRef]

24. Yuan, X.; Zhang, X.; Sun, L.; Wei, Y.; Wei, X. Cellular toxicity and immunological effects of carbon-based nanomaterials. Part. Fibre Toxicol. 2019, 16, 18. [CrossRef]

25. Allegri, M.; Perivoliotis, D.K.; Bianchi, M.G.; Chiu, M.; Pagliaro, A.; Koklioti, M.A.; Trompeta, A.F.; Bergamaschi, E.; Bussolati, O.; Charitidis, C.A. Toxicity determinants of multi-walled carbon nanotubes: The relationship between functionalization and agglomeration. Toxicol. Rep. 2016, 3, 230-243. [CrossRef] [PubMed] 
26. Fan, C.; Wang, D.A. A biodegradable PEG-based micro-cavitary hydrogel as scaffold for cartilage tissue engineering. Eur. Polym. J. 2015, 72, 651-660. [CrossRef]

27. Jafari, A.; Hassanajili, S.; Azarpira, N.; Karimi, M.B.; Geramizadeh, B. Development of thermal-crosslinkable chitosan/maleic terminated polyethylene glycol hydrogels for full thickness wound healing: In vitro and in vivo evaluation. Eur. Polym. J. 2019, 118, 113-127. [CrossRef]

28. Kaur, G.; Mehta, S.K. Developments of polysorbate (Tween) based microemulsions: Preclinical drug delivery, toxicity and antimicrobial applications. Int. J. Pharm. 2017, 529, 134-160. [CrossRef]

29. Vernon-Carter, E.J.; Alvarez-Ramirez, J.; Bello-Perez, L.A.; Garcia-Hernandez, A.; Roldan-Cruz, C.; Garcia-Diaz, S. In vitro digestibility of normal and waxy corn starch is modified by the addition of Tween 80. Int. J. Biol. Macromol. 2018, 116, 715-720. [CrossRef]

30. Tan, J.M.; Karthivashan, G.; Arulselvan, P.; Fakurazi, S.; Hussein, M.Z. Characterization and in vitro studies of the anticancer effect of oxidized carbon nanotubes functionalized with betulinic acid. Drug Des. Dev. Ther. 2014, 8, 2333-2343. [CrossRef]

31. Kura, A.U.; Hussein-Al-Ali, S.H.; Hussein, M.Z.; Fakurazi, S. Preparation of tween 80-Zn/Al-levodopa-layered double hydroxides nanocomposite for drug delivery system. Sci. World J. 2014. [CrossRef]

32. Vladimir, A.; Barrios, E.; Rangel Méndez, J.R.; Pérez Aguilar, N.V.; Espinosa, G.A.; Dávila Rodríguez, J.L. FTIR—An Essential Characterization Technique for Polymeric Materials. In Infrared Spectroscopy-Materials Science, Engineering and Technology, Theophile Theophanides; IntechOpen: Rijeka, Croatia, 2012; Available online: https://www.intechopen.com/books/infrared-spectroscopymaterials-science-engineering-and-technology / ftir-an-essential-characterization-technique-for-polymeric-materials (accessed on 29 March 2020).

33. Cîntă-Pînzaru, S.; Dehelean, C.A.; Soica, C.; Culea, M.; Borcan, F. Evaluation and differentiation of the Betulaceae birch bark species and their bioactive triterpene content using analytical FT-vibrational spectroscopy and GC-MS. Chem. Cent. J. 2012, 6, 67. [CrossRef] [PubMed]

34. Barbosa, H.F.G.; Francisco, D.S.; Ferreira, A.P.G.; Cavalheiro, E.T.G. A new look towards the thermal decomposition of chitins and chitosans with different degrees of deacetylation by coupled TG-FTIR. Carbohydr. Polym. 2019, 225, 115232. [CrossRef]

35. Avetta, P.; Nisticò, R.; Faga, M.G.; D’Angelo, D.; Aimo Boot, E.; Lamberti, R.; Martorana, S.; Calza, P.; Fabbri, D.; Magnacca, G. Hernia-repair prosthetic devices functionalized with chitosan and ciprofloxacin coating: Controlled release and antibacterial activity. J. Mater. Chem. B 2014, 2, 5287-5294. [CrossRef]

36. Salehi, A.M.; Moussavi, G.; Yaghmaeian, K. Preparation, characterization and catalytic activity of a novel mesoporous nanocrystalline $\mathrm{MgO}$ nanoparticle for ozonation of acetaminophen as an emerging water contaminant. Chem. Eng. J. 2017, 310, 157-169. [CrossRef]

37. Guidoin, M.F.; Yang, J.; Pichette, A.; Roy, C. Betulin isolation from birch bark by vacuum and atmospheric sublimation. A thermogravimetric study. Thermochim. Acta 2003, 398, 153-166. [CrossRef]

38. Kang, D.Y.; Pokharel, P.; Kim, Y.S.; Choi, S.; Choi, S.H. Poymer-grafted multiwalled carbon nanotube composites by a chemical grafting approach for supercapacitor application. J. Nanomater. 2015. [CrossRef]

39. Hsieh, Y.C.; Chou, Y.C.; Lin, C.P.; Hsieh, T.F.; Shu, C.M. Thermal analysis of multi-walled carbon nanotubes by Kissinger's corrected kinetic equation. Aerosol. Air. Qual. Res. 2010, 10, 212-218. [CrossRef]

40. Jeon, I.Y.; Baek, J.B. Nanocomposites derived from polymers and inorganic nanoparticles. Materials 2010, 3, 3654-3674. [CrossRef]

41. Jorio, A. Raman spectroscopy in graphene-based systems: Prototypes for nanoscience and nanometrology. ISRN Nanotechnol. 2012. [CrossRef]

42. Bokobza, L.; Bruneel, J.L.; Couzi, M. Raman spectra of carbon-based materials (from graphite to carbon black) and of some silicone composites. C J. Carbon Res. 2015, 1, 77-94. [CrossRef]

43. Matthews, M.J.; Pimenta, M.A.; Dresselhaus, G.; Dresselhaus, M.S.; Endo, M. Origin of dispersive effects of the Raman D band in carbon matereials. Phys. Rev. B 1999, 59, R6585. [CrossRef]

44. Sadezky, A.; Muckenhuber, H.; Grothe, H.; Niessner, R.; Pöschl, U. Raman microspectroscopy of soot and related carbonaceous materials: Spectral analysis and structural information. Carbon 2005, 43, 17311742. [CrossRef]

45. Dippel, B.; Heintzenberg, J. Soot characterization in atmospheric particles from different sources by NIR FT Raman spectroscopy. J. Aerol. Sci. 1999, 30, 907-908. [CrossRef]

46. Bystrzejewski, M.; Huczko, A.; Lange, H.; Gemming, T.; Büchner, B.; Rümmeli, M.H. Dispersion and diameter separation of multi-wall carbon nanotubes in aqueous solutions. J. Colloid Interface Sci. 2010, 345, 138-142. [CrossRef]

47. McNally, T.; Pötschke, P.; Halley, P.; Murphy, M.; Martin, D.; Bell, S.E.J.; Brennan, G.P.; Bein, D.; Lemoine, P.; Quinn, J.P. Polyethylene multiwalled carbon nanotubes composites. Polymer 2005, 46, 8222-8232. [CrossRef]

48. Mosmann, T. Rapid colorimetric assay for cellular growth and survival: Application to proliferation and cytotoxicity assays. J. Immunol. Methods 1983, 65, 55-63. [CrossRef]

49. Grobler, S.R.; Oliver, A.; Moodley, D.; Van Wyk Kotze, T.J. Cytotoxicity of recent dentin bonding agents on mouse fibroblast cells. Quintessence Int. 2008, 39, 511-516.

50. Theiszová, M.; Jantová, S.; Dragúnová, J.; Grznárová, P.; Palou, M. Comparison the cytotoxicity of hydroxyapatite measured by direct cell counting and MTT test in murine fibroblast NIH-3T3 cells. Biomed. Pap. Med. Fac. Univ. Palacky Olomouc Czech Repub. 2005, 149, 393-396. [CrossRef] 
51. Orsine, J.V.; Marques Brito, L.; Silva, R.C.; Santos Almeida Mde, F.; Novaes, M.R. Cytotoxicity of Agaricus sylvaticus in non-tumor cells (NIH/3T3) and tumor (OSCC-3) using tetrazolium (MTT) assay. Nutr. Hosp. 2013, 28, 1244-1254.

52. Todaro, G.J.; Green, H. Quantitative studies of the growth of mouse embryo cells in culture and their development into established lines. J. Cell Biol. 1963, 17, 299-313. [CrossRef] 